coloproctology 2022 $44: 440$

https://doi.org/10.1007/s00053-022-00596-y

Online publiziert: 24 . Februar 2022

(c) The Author(s), under exclusive licence to Springer Medizin Verlag GmbH, ein Teil von Springer Nature 2022

\section{Erratum zu: Chymus-Reinfusion als Therapieoption für enterokutane Fisteln}

\section{Ist das System praxistauglich?}

\section{Elisabeth Blüthner}

Medizinische Klinik m.S. Hepatologie und Gastroenterologie CCM/CVK, Charité - Universitätsmedizin Berlin, Berlin, Deutschland

\section{Erratum zu:}

coloproctology 2021

https://doi.org/10.1007/s00053-021-

00566-w

Der Artikel "Chymus-Reinfusion als Therapieoption für enterokutane Fisteln" von Elisabeth Blüthner wurde ursprünglich am 25. Oktober 2021 mit „Open Access" online auf der Internetplattform des Verlags unter der Lizenz Creative Commons Attribution (CC BY) license 4.0 veröffentlicht.

Nach der Veröffentlichung in Band 43 Heft 6 pp. 422-424 entschied/en sich der/die Autor(en) den „Open Access" zu stornieren. Das Urheberrecht des Artikels wurde deshalb am 31. Januar 2022 to (c) The Author(s), under exclusive licence to Springer Medizin Verlag $\mathrm{GmbH}$, ein Teil von Springer Nature 2021 unter Vorbehalt aller Rechte geändert.

\section{Korrespondenzadresse}

\section{Dr. med. Elisabeth Blüthner}

Medizinische Klinik m.S. Hepatologie und Gastroenterologie CCM/CVK, Charité Universitätsmedizin Berlin Charitéplatz 1, 10117 Berlin, Deutschland elisabeth.bluethner@charite.de
Die Online-Version des Originalartikels ist unter https://doi.org/10.1007/s00053-021-00566-w zu finden. 